\title{
Perturbed Insulin-like Growth Factor-1 (IGF-1) and IGF Binding Protein-3 Are Not Associated with Chronic Widespread Pain in Men: Results from the European Male Ageing Study
}

JOHN McBETH, ABDELOUAHID TAJAR, TERENCE W. O'NEILL, GARY J. MACFARLANE, STEPHEN R. PYE, GYORGY BARTFAI, STEVEN BOONEN, ROGER BOUILLON, FELIPE CASANUEVA, JOSEPH D. FINN, GIANNI FORTI, ALEKSANDER GIWERCMAN, THANG S. HAN, ILPO T. HUHTANIEMI, KRZYSZTOF KULA, MICHAEL E.J. LEAN, NEIL PENDLETON, MARGUS PUNAB, ALAN J. SILMAN, DIRK VANDERSCHUEREN, FREDERICK C.W. WU, and the EMAS Group

ABSTRACT. Objective. To determine whether perturbations of insulin-like growth factor-1 (IGF-1) and IGF binding protein-3 (IGFBP-3) were associated with the presence of chronic widespread pain (CWP) in men.

Methods. The European Male Ageing Study (EMAS) is an 8-center population-based study of men aged 40-79 years recruited from population registers. A questionnaire asked about the presence and duration of musculoskeletal pain, from which subjects reporting CWP were identified. Subjects also had an interviewer-assisted questionnaire: levels of physical activity and mood were assessed, and height and weight were measured. IGF-1 and IGFBP-3 were assayed from a fasting blood sample. Logistic regression models were used to determine the association between IGF measures and CWP. Results were expressed as odds ratios or relative risk ratios.

Results. A total of 3206 subjects provided full data. Of those, 1314 (39.0\%) reported no pain in the past month and $278(8.3 \%)$ reported pain that satisfied criteria for CWP. IGF-1 concentrations were similar among subjects who reported no pain and those with CWP: $131.5 \mathrm{mg} / \mathrm{l}$ and $128.4 \mathrm{mg} / \mathrm{l}$, respectively. This was true also for IGFBP-3 (4.3 and $4.3 \mathrm{mg} / \mathrm{l})$. Obesity was associated with low IGF-1 and a high IGFBP-3/IGF-1 ratio, indicating less bioavailable IGF-1, irrespective of pain status. This relationship persisted after adjustment for comorbidities, depression, smoking, alcohol consumption, and quality of life.

Conclusion. Overall CWP was not associated with perturbations in IGF-1 and IGFBP-3 concentrations. Hypofunctioning of the axis was noted among subjects who were obese and this was not specific to CWP. These data suggest that IGF-1 is unlikely to be etiologically important in relation to CWP, although the relationship with growth hormone remains to be elucidated. (First Release Oct 15 2009; J Rheumatol 2009;36:2523-30; doi:10.3899/jrheum.090113)

Key Indexing Terms:

INSULIN-LIKE GROWTH FACTOR-1 CHRONIC PAIN INSULIN-LIKE GROWTH FACTOR BINDING PROTEIN-3

EPIDEMIOLOGY MEN POPULATION STUDY
From the ARC Epidemiology Unit, The University of Manchester, Manchester, UK; Aberdeen Pain Research Collaboration (Epidemiology Group), University of Aberdeen, Aberdeen, UK; Department of Obstetrics, Gynaecology and Andrology, Albert Szent-Gyorgy Medical University, Szeged, Hungary; Division of Gerontology and Geriatrics and Centre for Musculoskeletal Research, Department of Experimental Medicine, Katholieke Universiteit Leuven; Laboratory of Experimental Medicine and Endocrinology, Katholieke Universiteit Leuven; Department of Andrology and Endocrinology, Katholieke Universiteit Leuven, Leuven, Belgium; Department of Medicine, Santiago de Compostela University, Complejo Hospitalario Universitario de Santiago (CHUS), and CIBER de Fisiopatología Obesidad y Nutricion (CB06/03), Instituto Salud Carlos III, Santiago de Compostela, Spain; Andrology Unit, Department of Clinical Physiopathology, University of Florence, Florence, Italy; Reproductive Medicine Centre, Malmö University Hospital, University of Lund, Lund, Sweden; Department of Endocrinology, Royal Free and University College Hospital Medical School, Royal Free Hospital, London, UK; Department of Reproductive Biology, Imperial College London, Hammersmith Campus, London, UK; Department of Andrology and Reproductive Endocrinology, Medical University of Lodz, Lodz, Poland; Department of Human Nutrition, University of Glasgow, Glasgow, Scotland; Clinical Gerontology, The University of Manchester, Hope Hospital, Salford, UK; Andrology Unit, United Laboratories of Tartu University Clinics, Tartu, Estonia; and Department of Endocrinology, Manchester Royal Infirmary, The University of Manchester, Manchester, UK.

The European Male Ageing Study (EMAS) is funded by the Commission of the European Communities Fifth Framework Programme "Quality of Life and Management of Living Resources" Grant QLK6-CT-2001-00258. Additional support was also provided by the Arthritis Research Campaign. Dr. Boonen is senior clinical investigator of the Fund for Scientific Research, Flanders, Belgium (F.W.O.-Vlaanderen), and holder of the Leuven University Chair in Metabolic Bone Diseases. J. McBeth, MD; A. Tajar, PhD; T.W. O'Neill, MD, ARC Epidemiology Unit, The University of Manchester; G.J. Macfarlane, MD, PhD, Aberdeen Pain Research Collaboration (Epidemiology Group), University of Aberdeen; S.R. Pye, MSc, ARC Epidemiology Unit, The University of 
Manchester; G. Bartfai, MD, Department of Obstetrics, Gynaecology and Andrology, Albert Szent-Gyorgy Medical University; S. Boonen, MD, $P h D$, Division of Gerontology and Geriatrics and Centre for Musculoskeletal Research, Department of Experimental Medicine, Katholieke Universiteit Leuven; R. Bouillon, MD, PhD, Laboratory of Experimental Medicine and Endocrinology, Katholieke Universiteit Leuven; F. Casanueva, MD, PhD, Department of Medicine, Santiago de Compostela University, Complejo Hospitalario Universitario de Santiago (CHUS), and CIBER de Fisiopatología Obesidad y Nutricion (CB06/03), Instituto Salud Carlos III; J.D. Finn, BSc, ARC Epidemiology Unit, The University of Manchester; G. Forti, MD, Andrology Unit, Department of Clinical Physiopathology, University of Florence; A. Giwercman, MD, PhD, Reproductive Medicine Centre, Malmö University Hospital, University of Lund; T.S. Han, MD, PhD, Department of Endocrinology, Royal Free and University College Hospital Medical School, Royal Free Hospital; I.T. Huhtaniemi, MD, PhD, Department of Reproductive Biology, Imperial College London; K. Kula, MD, PhD, Department of Andrology and Reproductive Endocrinology, Medical University of Lodz; M.E.J. Lean, MD, Department of Human Nutrition, University of Glasgow; N. Pendleton, MD, Clinical Gerontology, The University of Manchester; M. Punab, MD, Andrology Unit, United Laboratories of Tartu University Clinics; A.J. Silman, MD, ARC Epidemiology Unit, The University of Manchester; D. Vanderschueren, MD, PhD; F.C.W. Wu, MD, Department of Andrology and Endocrinology, Katholieke Universiteit Leuven.

Address correspondence to Dr. J. McBeth, ARC Epidemiology Unit, Oxford Road, The University of Manchester, Manchester, M13 9PT United Kingdom. E-mail: john.mcbeth@manchester.ac.uk

Accepted for publication June 3, 2009.

Fibromyalgia (FM) is a noninflammatory rheumatic disorder characterized by chronic widespread musculoskeletal pain (CWP) in the presence of generalized tenderness ${ }^{1}$. Symptoms are associated with high levels of disability and poor health-related quality of $\operatorname{life}^{2}$. Although the pathophysiology of this chronic pain condition remains unclear, central and peripheral stress-related mechanisms that influence pain signaling and perception appear to be involved ${ }^{3}$. A strong relationship between altered functioning of the hypothalamic-pituitary-adrenal stress axis and the onset of CWP has been reported ${ }^{4}$. Specifically among subjects at risk of developing CWP, those with low morning and high evening salivary cortisol levels were 12 times more likely to develop symptoms one year later. Hypofunctioning of the related hypothalamic-pituitary-insulin-like growth factor-1 (IGF-1) axis has also been reported to be related to $\mathrm{CWP}^{5}$. Patients with FM are reported to have inadequate time in deep sleep $^{6}$. Up to $80 \%$ of growth hormone $(\mathrm{GH})$ is made in stages III and IV of sleep and IGF-1 is thought to reflect the integrated $\mathrm{GH}$ pulses over the previous 48 hours. Patients with FM often describe pain arising from muscles and other deep tissues. Low levels of circulating GH may, by way of inefficient repair of muscle micro-trauma, explain the presence of CWP in these patients. Establishing a relationship between CWP and dysfunctioning of the IGF-1 axis would have important implications for development of treatment.

A recent review identified 23 observational studies of GH-IGF-1 axis functioning in patients with $\mathrm{FM}^{7}$. Overall, low concentrations of IGF-1 were found among some although not all subjects, with some studies failing to repli- cate the observation of low levels of IGF- $1^{8}$. GH stimulation tests often revealed a suboptimal response, which did not always correlate with IGF-1 levels. No consistent defects in pituitary function were found. Currently, the true relationship between IGF-1 axis functioning and CWP remains unclear.

Low levels of physical activity ${ }^{9}$, and clinical factors including obesity ${ }^{10}$ and high levels of psychological distress, particularly depression and anxiety disorders ${ }^{11}$, are common among subjects with CWP. Similar factors are associated with reductions in GH-IGF-1 levels ${ }^{12-16}$. It is plausible that these factors may act as confounders and explain the reported observations of reduced levels of IGF-1 in subsets of FM patients ${ }^{17,18}$. That is, low levels of IGF-1 would not be associated with pain per se but rather with the factors that co-occur with pain.

The aim of this study was to test the hypothesis that CWP would be associated with lower levels of IGF-1 and IGFBP-3. The secondary aim was to determine whether previous observations of reduced IGF-1 and IGFBP-3 levels among subjects with CWP could be explained by low levels of physical activity, obesity, and depression.

\section{MATERIALS AND METHODS}

A population-based cross-sectional study, the European Male Ageing Study (EMAS), was conducted. The detailed methodologies and full details have been published ${ }^{19}$. In brief, a total of 3369 subjects aged $40-79$ years were recruited from population registers in 8 European centers: Manchester, UK, Leuven, Belgium, Malmö, Sweden, Tartu, Estonia, Lodz, Poland, Szeged, Hungary, Florence, Italy, and Santiago de Compostela, Spain. All subjects were invited to attend for assessments that included a self-completed lifestyle questionnaire, blood test, and physical performance measures. The standardized and validated questionnaires gathered information on sociodemographic factors, general health status, smoking, and alcohol consumption. Height and weight were measured in the standing position. Body mass index (BMI) was calculated as body weight $(\mathrm{kg})$ divided by square of height $\left(\mathrm{m}^{2}\right)$. Data self-reported on comorbid conditions included heart conditions, high blood pressure, bronchitis, asthma, peptic ulcer, epilepsy, diabetes, cancer, liver conditions, kidney conditions, prostate diseases, and thyroid disorders.

The assessment also included the following.

1. The Physical Performance Test ${ }^{20}$ (PPT), a direct observational test that assesses multiple dimensions of physical function (basic and complex activities of daily living) with different levels of difficulty. Activities include writing a sentence and placing a book on a shelf. For the current analysis data gathered during the 50-foot walk test was used as an indicator of physical performance. This test requires subjects, on the command "go," to walk 50 feet. The time to complete the task is recorded; higher scores indicate faster walking as a proxy for lower extremity physical performance.

2. The Short-Form 36 (SF-36) ${ }^{21}$ questionnaire is an inventory originally designed to assess health status in the Medical Outcomes Study. Questions gather information on 8 health concepts including physical functioning, role limitations due to physical and emotional health, mental health, bodily pain, general health, vitality, and social functioning. These items are scored using a norm-based method providing a component summary scale score for both mental (SF36-MCS) and physical (SF36-PCS) health-related quality of life. A lower score on the summary scales represents poorer health-related quality of life.

3. The Beck Depression Inventory (BDI), a 21-item scale with each item scored between 0 and 3 with a total score between 0 and 63 , was included 
to measure the presence and severity of depressive symptoms ${ }^{22}$, higher scores indicating more depressive symptoms.

Ascertainment of pain status. All subjects were asked, "In the past month have you had any pain which has lasted for one day or more?" Subjects who responded negatively were classified as having "no pain." If subjects answered positively, they were asked to indicate the site(s) of pain on a body manikin with views of the front, back, and both sides. To assess chronicity, subjects were asked whether they had been aware of the pain for 3 months or more. CWP was classified using the definition in the American College of Rheumatology criteria for $\mathrm{FM}^{1}$. These criteria require pain, lasting at least 3 months, above and below the waist, on the right and left sides of the body, and in the axial skeleton. Subjects who reported pain that did not satisfy these criteria were classified as having "other pain." This instrument has been frequently used in population surveys and its construct validity demonstrated ${ }^{23,24}$. The methods chosen to assess pain (body manikins) were less language-dependent than alternatives. Nevertheless the stem question to the manikins did require translating into each center's language. This was done (for the whole questionnaire) by professional translation of the questionnaire from English, and back-translation by the centers' staff with a consensus conference arranged thereafter to resolve any discrepancies between the original and back-translated versions.

IGF assays. A single fasting morning (before 10:00 A.M.) venous blood sample was obtained and assayed. Quimioluminescence was used for IGF-1 and IGFBP-3. Serum analyses were performed in a single laboratory (Molecular Endocrinology, Faculty of Medicine, University of Santiago de Compostela, Spain). Within- and between-assay coefficients of variation for IGF-1 were $7.4 \%$ and $2.9 \%$ and for IGFBP-3 were $7.2 \%$ and $4.2 \%$. Detection limits of the respective assays were $20 \mathrm{ng} / \mathrm{ml}$ and $0.1 \mu \mathrm{g} / \mathrm{ml}$ for IGF-1 and IGFBP-3.

Ethical approval for the study was obtained in accord with local institutional requirements in each center. All subjects provided written informed consent.

Data manipulation and statistical analysis. The different variables were manipulated for analysis as follows.

Endocrine data: Subjects were categorized into one of 3 equal-size groups based upon the distribution of levels of IGF-1 and IGFBP-3 and the ratio of IGFBP-3/IGF- $1^{16}$. The ratio of IGFBP-3/IGF-1 is considered to reflect levels of circulating bioavailable IGF-1, higher values of this ratio reflecting lower levels of IGF-125.

BMI: Subjects were categorized as "not obese" (BMI $\left.\leq 30 \mathrm{~kg} / \mathrm{m}^{2}\right)$ and "obese" (BMI > $30 \mathrm{~kg} / \mathrm{m}^{2}$ ) following recommendations in the World Health Organisation's Global Strategy on Diet, Physical Activity and Health (available from: http://www.who.int/dietphysicalactivity/publications/facts/obesity/en/)

General health: Subjects were divided into those reporting none, and one or more comorbidities.

Physical activity: PPT 50-foot walk times were categorized as "fast" (range 7.2-15.2 s) and "slow" (highest quintile, range 15.3-42.7 s).

Depression: Score of $0-9$ on the BDI indicates that a person is not depressed, 10-18 mild-moderate depression, 19-29 moderate-severe depression, and 30-63 severe depression ${ }^{22}$. For our analysis BDI scores were categorized as "no depressive symptoms" (score 0-9) and "depressive symptoms" (score 10-63).

SF-36 physical and mental component scores were categorized into 3 equal-size groups based on the distribution of subjects' scores.

Smoking status: subjects were categorized as never smoker, ex-smoker, and current smoker.

Alcohol consumption: subjects were categorized as none (no days per week), infrequent ( 1 to 4 days per week), and frequent ( $\geq 5$ days per week)

All analyses were restricted to cases with complete data on all variables. As a test of the hypotheses the analysis compared the 2 groups at the extremes in terms of self-reported pain: those with no pain and those with CWP. The distributions of the 4 selected indices of GH-IGF-1 axis function were plotted separately for those subjects with CWP and those with no pain using kernel-density estimates. ANOVA was used to determine the signifi- cance of any observed differences for age, Kruskal-Wallis test for difference in IGF parameters, while chi-square tests were used for categorical variables. To test the main hypothesis, multiple logistic regression models with robust standard errors to take into account the hierarchy of the study design (individuals nested within centers) were used to quantify the relationship between CWP and the IGF variables. The comparison group comprised those reporting no pain. Separate models were constructed for each of the IGF variables, with all models adjusted for age. To test the second hypothesis, subjects within pain groups were then stratified according to their BMI (not obese/obese), number of comorbidities (0 vs 1 or more), PPT 50-foot walk test (low/high), and BDI (not depressed/depressed) scores to form 4 groups for analysis. For example, subjects were stratified as "no pain, not obese," "no pain, obese," "CWP, not obese," and "CWP, obese." Multinomial regression models were then constructed to examine the relationship of these categories as dependent variables with the IGF variables. Finally, these models were adjusted for the effects of alcohol and smoking and other putative confounders where appropriate.

The results are expressed as odds ratios for logistic regression, and relative risk ratios for multinomial models with $95 \%$ confidence intervals. All statistical analyses were conducted using Intercooled Stata version 9.22 (Stata Corp., College Station, TX, USA)

\section{RESULTS}

Of the 3369 participants, $3206(95.1 \%)$ provided full data on pain status and were available for the current analysis. Of those, 1314 (39.0\%) reported no pain in the past month, 278 (8.3\%) reported pain that satisfied the ACR criteria for CWP, while 1614 (47.9\%) were classified as having "other pain" and were excluded from further analysis. There were no significant differences in age when subjects with CWP were compared to those who were pain-free (Table 1). The distribution of IGF variables was also similar across pain groups. However, those with CWP were more likely to be classified as obese, to report at least one comorbidity, to take longer to complete the 50-foot walk test, have depressive symptoms, have low SF-36 scores, and currently smoke; and they were less likely to consume alcohol "frequently."

Relationship between pain status and IGF variables. Among subjects with CWP the distribution of levels of IGF-1 [the probability density function shows the distribution of the IGF variables separately by pain group; Figure 1 . Median $=128.4 \mathrm{mg} / \mathrm{l}$, interquartile range (IQR) 100.3-148.1 $\mathrm{mg} / \mathrm{l}$ ] did not differ significantly from those observed among pain-free subjects (median $=131.5 \mathrm{mg} / \mathrm{l}$, IQR $102.5-155.2 \mathrm{mg} / \mathrm{l}$; chi-square $=0.12, \mathrm{p}=0.17)$. Similarly, distributions of levels of IGFBP-3 (CWP median $=4.3 \mathrm{mg} / \mathrm{l}$, IQR 3.6-4.9 mg/l; "No pain" median = $4.3 \mathrm{mg} / \mathrm{l}$, IQR 3.7, $5.0 \mathrm{mg} / \mathrm{l}$; chi-square $=0.28, \mathrm{p}=0.19$ ) did not differ between the 2 groups. Reporting CWP was associated with a modest increase in the odds of being in the middle and lowest third of IGF-1 and IGFBP 3 and the middle and highest third of the IGFBP-3/IGF-1 ratio (Table 2), although the majority of these relationships were not significant.

Relationship between clinical factors and IGF variables. On examination of the relationship between clinical factors and IGF-1 levels (Table 3) there was no influence of CWP in non-obese subjects (OR 1.27, 95\% CI 0.82, 1.96). By con- 
Table 1. Subject characteristics for the entire sample and separately by pain status. Values are $\mathrm{N}$ (\%) (unless otherwise indicated).

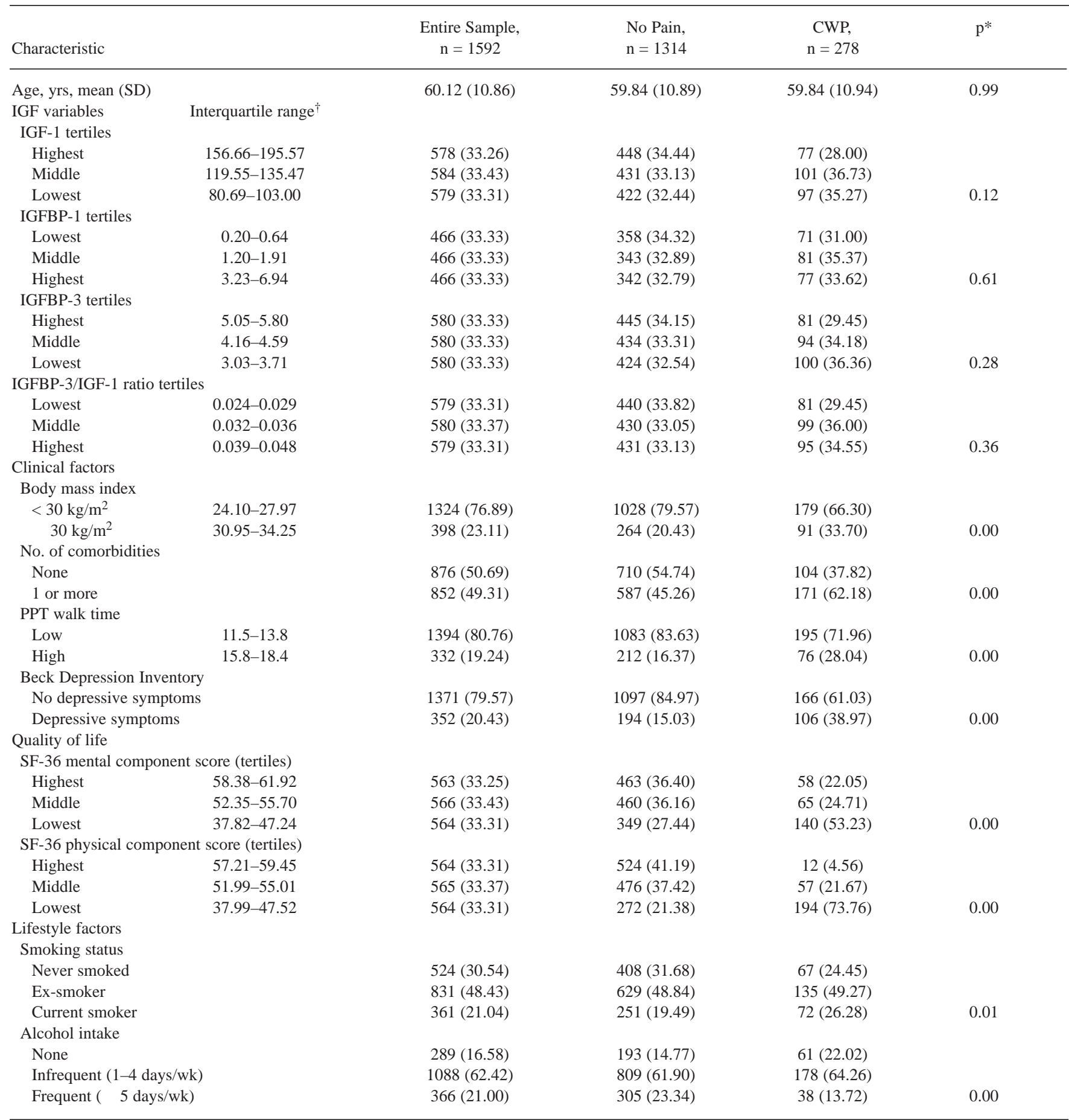

* For ANOVA (age) test of independence for categorical variables. ${ }^{\dagger}$ Where appropriate. CWP: chronic widespread pain; IGF: insulin-like growth factor; BP: binding protein; PPT: Physical Performance Test.

trast, those who were obese and reported no pain (OR 1.46, 95\% CI $0.89,2.39$ ) or CWP (OR 1.98, 95\% CI 1.03, 3.81) had an increased risk of being in the lowest third of IGF-1. Obesity was also associated with being in the middle and highest thirds of the IGFBP-3/IGF-1 ratio for both pain-free and CWP subjects. Reporting $\geq 1$ comorbidities, taking $\geq$ $15.2 \mathrm{~s}$ to walk 50 feet, and depression were associated with being in the lowest third of IGF-1 in both pain groups. Similar associations were observed for IGFBP-3 levels.

Adjustment for factors associated with hypofunctioning of Personal non-commercial use only. The Journal of Rheumatology Copyright (C) 2009. All rights reserved. 

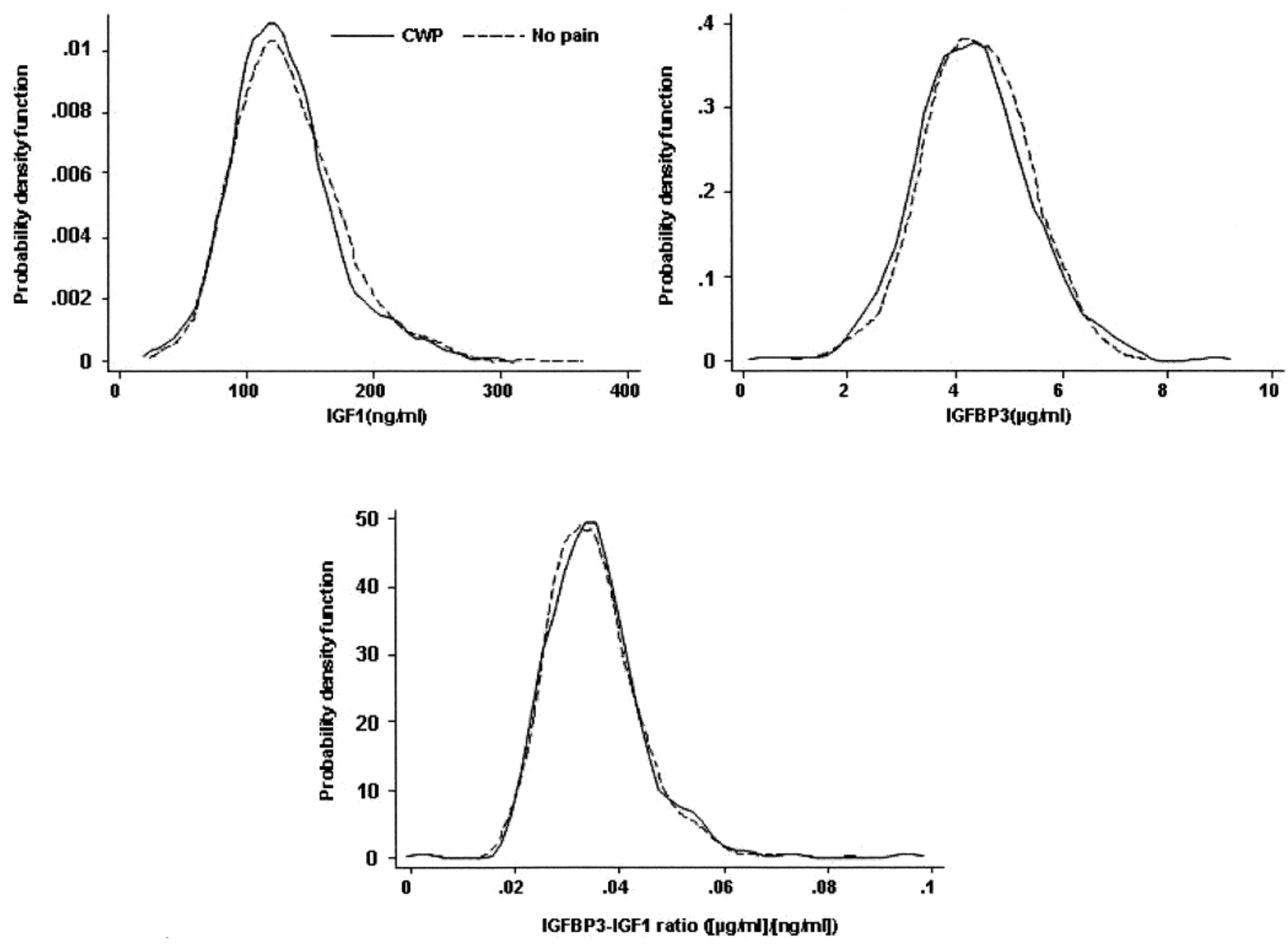

Figure 1. Distribution of IGF-1, IGFBP-3, and IGFBP-3/IGF-1 by pain status.

the GH-IGF-1 axis. After adjustment for smoking, alcohol consumption, and SF-36 score, it was clear that the majority

Table 2. IGF-1, IGFBP-3, and IGFBP-3/IGF-1 in subjects with chronic widespread pain compared to those with no pain: logistic regression models adjusted for age. Robust standard errors were used to account for center.

\begin{tabular}{lcc}
\hline & $\begin{array}{c}\text { Unadjusted } \\
\text { RRR }(95 \% \text { CI })\end{array}$ & $\begin{array}{c}\text { Adjusted } \\
\text { RRR }(95 \% \mathrm{CI})\end{array}$ \\
\hline $\begin{array}{l}\text { IGF-1 tertiles } \\
\text { Highest }\end{array}$ & Referent & Referent \\
Middle & $1.36(0.98,1.90)$ & $1.39(1.01,1.90)^{*}$ \\
Lowest & $1.34(0.92,1.94)$ & $1.39(0.89,2.15)$ \\
IGFBP-3 tertiles & & \\
Highest & Referent & Referent \\
Middle & $1.19(0.79,1.78)$ & $1.20(0.78,1.85)$ \\
Lowest & $1.30(1.02,1.65)^{*}$ & $1.34(1.01,1.77)^{*}$ \\
IGFBP-3/IGF-1 ratio tertiles & & \\
Lowest & Referent & Referent \\
Middle & $1.25(0.92,1.69)$ & $1.25(0.93,1.69)$ \\
Highest & $1.20(0.80,1.80)$ & $1.20(0.80,1.81)$ \\
\hline
\end{tabular}

$* \mathrm{p}<0.05$. RRR: relative risk ratio. of the observed associations were explained by these factors (Table 4), since the relationships were attenuated towards the null. Notably, obesity was more likely to be a predictor of being in the middle and highest thirds of IGFBP-3/IGF-1 ratio independently of pain status. Interestingly, in this analysis obesity was less likely to be a predictor of being in the middle and lowest thirds of IGFBP-3.

\section{DISCUSSION}

There were no differences in functioning of the IGF-1 axis (measured by IGF-1 and IGFBP-3, and free IGF-1) among subjects with CWP compared to those who were pain-free. These results are in contrast to previous reports of a hypofunctioning IGF-1 axis. It was hypothesized that hypofunctioning of the IGF-1 axis may be associated with additional factors among subsets of subjects with CWP. Obesity was significantly associated with low IGF-1 and low free IGF-1 levels both in subjects with CWP and in those who were pain-free, indicating that the relationship was independent of pain status. The relationships with low free IGF-1 levels persisted after adjustment for other factors known to influ- 
Table 3. IGF-1, IGFBP-3, and IGFBP-3/IGF-1, and chronic widespread pain (CWP) stratified by body mass index (BMI), comorbidity, Physical Performance Test (PPT) walk time*, and Beck Depression Inventory (BDI) ${ }^{\dagger}$; unadjusted multinomial logistic regression models. Base categories are Model 1 "No pain/normal BMI" ( $\mathrm{n}=1028,65.81 \%)$, Model 2 "No pain/no morbidity" ( $\mathrm{n}=710,45.17 \%)$, Model 3 "No pain/fast PPT walk time" ( $\mathrm{n}=1083,69.16 \%)$, Model 4 "No pain/no depressive symptoms" $(\mathrm{n}=1097,70.19 \%)$. Data are relative risk ratios $(95 \% \mathrm{CI})$.

\begin{tabular}{|c|c|c|c|c|c|c|}
\hline & \multicolumn{2}{|c|}{$\begin{array}{c}\text { IGF-1 } \\
\text { Referent: Highest Tertile }\end{array}$} & \multicolumn{2}{|c|}{$\begin{array}{c}\text { IGFBP-3 } \\
\text { Referent: Highest Tertile }\end{array}$} & \multicolumn{2}{|c|}{$\begin{array}{l}\text { IGFBP-3/IGF-1 Ratio } \\
\text { Referent: Lowest Tertile }\end{array}$} \\
\hline & Middle & Lowest & Middle & Lowest & Middle & Highest \\
\hline No Pain, obese & $0.98(0.64,1.51)$ & $1.46(0.89,2.39)$ & $0.69(0.57,0.84)$ & $0.76(0.56,1.03)$ & $1.54(1.00,2.38)^{* *}$ & $2.01(1.27,3.20)^{* *}$ \\
\hline CWP, not obese & $1.30(0.92,1.85)$ & $1.27(0.82,1.96)$ & $1.34(0.90,2.01)$ & $1.38(0.88,2.17)$ & $1.25(0.97,1.61)$ & $0.97(0.61,1.54)$ \\
\hline CWP, obese & $1.57(0.98,2.52)$ & $1.98(1.03,3.81)^{* *}$ & $0.69(0.32,1.49)$ & $1.06(0.77,1.46)$ & $1.44(0.67,3.07)$ & $2.50(1.33,4.71)^{* *}$ \\
\hline \multicolumn{7}{|c|}{ Model 2: stratified by no. of comorbidities } \\
\hline CWP, 0 symptoms & $1.22(0.76,1.98)$ & $0.98(0.46,2.08)$ & $1.41(0.84,2.36)$ & $1.03(0.43,2.45)$ & $1.06(0.62,1.84)$ & $1.06(0.57,1.98)$ \\
\hline $\mathrm{CWP}, \geq 1$ symptoms & $1.92(1.35,2.72)^{* *}$ & * $2.85(1.81,4.51)^{* * *}$ & $1.28(0.79,2.10)$ & $2.58(2.01,3.31)$ & $1.47(0.89,2.42)$ & $1.55(0.88,2.73)$ \\
\hline \multicolumn{7}{|c|}{ Model 3: Stratified by PPT time to walk 50 feet } \\
\hline No pain, slow PPT time & $1.37(0.85,2.20)$ & $1.91(1.10,3.31)^{* *}$ & $1.46(0.98,2.17)$ & $2.20(1.32,3.65)^{* *}$ & $0.86(0.64,1.15)$ & $0.97(0.69,1.38)$ \\
\hline CWP, fast PPT time & $1.40(0.87,2.26)$ & $1.20(0.90,1.59)$ & $1.04(0.76,1.42)$ & $1.19(0.88,1.60)$ & $1.12(0.87,1.45)$ & $1.03(0.73,1.46)$ \\
\hline CWP, slow PPT time & $1.49(0.85,2.63)$ & $2.69(1.17,6.21)^{* *}$ & $1.94(0.95,3.99)$ & $3.02(1.73,5.27)^{* *}$ & $1.46(0.91,2.34)$ & $1.69(0.77,3.70)$ \\
\hline
\end{tabular}

$*$ Fast PPT walk time defined as $\leq 15.2 \mathrm{~s}$ ( $80 \%$ centile), slow if $\geq 15.3 \mathrm{~s}$ ! No depressive symptoms: classified as normal; depressive symptoms: classified
as mild to extreme. Depressive symptoms corresponds to $20 \%$ of the entire sample. Robust standard errors were used to account for center. $* * \mathrm{p}<0.05$.

Table 4. IGF-1, IGFBP-3, and IGFBP-3/IGF-1 ratio and chronic widespread pain (CWP) stratified by body mass index (BMI), comorbidity, Physical Performance Test (PPT) walk time, and Beck Depression Inventory (BDI). Multinomial logistic regression models adjusted for age, smoking status, alcohol intake, SF-36 mental component score, SF-36 physical component score, and where appropriate BMI, morbidity, PPT walk time, BDI. Center was incorporated using robust standard errors. Base categories are Model 1 "No pain/normal BMI," Model 2 "No pain/no morbidity," Model 3 "No pain/fast PPT walk time," Model 4 "No pain/no depressive symptoms." Data are relative risk ratios (95\% CI).

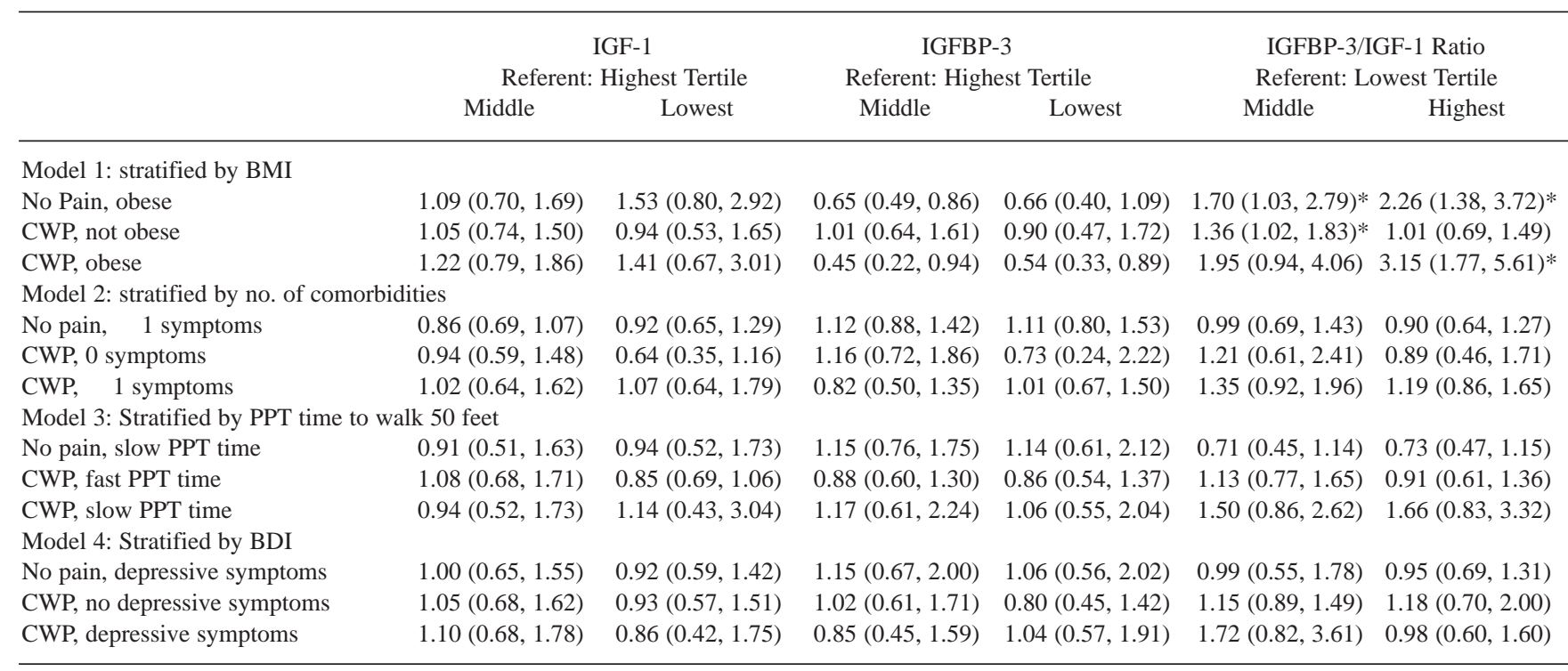

$* \mathrm{p}<0.05$.

ence functioning of the IGF-1 axis, including smoking, alcohol consumption, and quality of life.

Before consideration of the implications of these observations a number of methodological issues must be high-lighted. First, a number of subjects who were invited to take part did not do so $(\mathrm{n}=4453,53 \%)$. Nonresponders

were more likely to be younger [mean age (SD): participants 60.0 yrs (11.0), nonparticipants 62.8 yrs (11.7)]. IGF-1 axis functioning shows an age-related decline. It is likely that in this study the proportion of men with lower levels of IGF-1 and IGFBP-3 has been overestimated. Nevertheless, for this nonparticipation to influence these findings one would have 
to hypothesize that the relationship between the IGF variables and pain status was different in those that did and did not participate. Further, factors that would be associated with participation in the study and that would also moderate the relationship between pain and IGF-1 axis functioning would need to be identified. While this must remain a possibility, it is difficult to identify such a factor. Second, there are a number of unmeasured confounders that may influence the relationships reported. For example, sleep is strongly associated with reporting CWP and with GH-IGF-1 axis functioning ${ }^{26}$. Previous studies have suggested altered functioning of the GH-IGF-1 axis in clinic patients with FM. This hypothesis originally developed from observations of poor sleep in FM patients, and particularly stages 3 and 4 of non-rapid eye movement sleep ${ }^{27}$, the stages of sleep during which GH production occurs. Third, the number of illnesses subjects reported were summed to estimate the effect of the number of comorbidities. This approach does not take into consideration the duration or severity of the illnesses. Future studies could usefully include a more refined measure of comorbidity such as the Charlson Index ${ }^{28}$. Finally, a number of variables were categorized to be included in the analysis and while some of these will be clinically meaningful (e.g., subjects who are obese using standard criteria of a BMI $\geq$ 30) the clinical usefulness of others (e.g., number of comorbidities) is unclear.

In one of the first reports to explore the relationship, Bennett and colleagues ${ }^{29}$ reported highly significant lower levels of IGF-1 in FM patients compared to "healthy" controls (mean $124.7 \pm 47 \mathrm{ng} / \mathrm{ml}$ vs $175.2 \pm 60 \mathrm{ng} / \mathrm{ml}$, respectively; $\mathrm{p}=0.000001$ ). This result was confirmed in a subsequent report from the same group ${ }^{5}$, with lower mean IGF-1 levels among 552 patients with FM $(138 \pm 56 \mathrm{ng} / \mathrm{ml})$ compared to 152 controls $(215 \pm 68 \mathrm{ng} / \mathrm{ml} ; 74$ blood donors, 26 myofascial pain patients, 52 patients with "other" rheumatic diseases). Others have reported that even when IGF-1 levels are similar, FM patients have lower levels of $\mathrm{GH}^{30}$. While FM patients have been reported to exhibit decreased spontaneous $\mathrm{GH}$ secretion they have a similar response to GH-releasing hormone, suggesting normal pituitary responsiveness and a probable defect at the hypothalamic level ${ }^{31}$. Levels of $\mathrm{GH}$ were not measured and the relationship between CWP and GH levels in this study population remains unclear. It is possible that despite the similar levels of IGF-1 and IGFBP-3, subjects with CWP may have lower levels of $\mathrm{GH}$. However, these findings are not consistent. Others have reported no difference in urinary excretion of $\mathrm{GH}^{32}$, nonstimulated serum levels of $\mathrm{GH}^{8}$, IGF-1 ${ }^{8,18,32,33}$, or serum IGFBP-3 $3^{8,33}$. Generally, these studies are methodologically limited by small numbers of subjects that, coupled with the variation in $\mathrm{GH}$ axis functioning, may explain the equivocal results.

If low GH-IGF-1 levels were important in the etiology of FM one would expect that treatment with GH would lead to symptomatic improvement. Physical activity is known to improve FM symptoms, although GH and IGF-1 levels did not change following a strength training program and could not therefore explain any improvement in symptoms ${ }^{34}$. Similarly, 6 months of exercise and pyridostigmine normalized the $\mathrm{GH}$ response to exercise at $\mathrm{VO}_{2}$ maximum, but did not significantly correct IGF-1 or IGFBP- $3^{35}$. A small treatment study $(n=8)$ reported that treating FM patients with human GH increased serum levels of IGF-1 and IGFBP-3 ${ }^{31}$. One randomized controlled trial of $\mathrm{GH}$ treatment reported that 9 months of daily injected recombinant GH reduced FM symptoms and normalized IGF- $1^{36}$. A pilot study reported a reduction in mean number of tender points and improvements in Fibromyalgia Impact Questionnaire scores ${ }^{37}$ and quality of life among FM patients receiving 0.0125 $\mathrm{mg} / \mathrm{kg} /$ day of $\mathrm{GH}$ in addition to standard therapy, compared to patients receiving standard therapy alone ${ }^{38}$.

Among subjects with CWP there was evidence of increased odds of perturbed functioning of the IGF-1 axis among subjects who were obese. This relationship was also apparent among subjects reporting no pain, but not among subjects with CWP who were not obese. This observation is supported by data showing IGF-1 axis function is perturbed in individuals who are obese ${ }^{12}$, although the temporal nature of this relationship is unclear. In a study that examined serum IGF-1 levels of 57 FM patients, only 4 subjects were found to have levels below normal ranges (79-372 ng/ml) ${ }^{17}$. Among study subjects, $32(56 \%)$ were classified as normal/overweight BMI ( $\leq 30 \mathrm{~kg} / \mathrm{m}^{2}$ ) while 25 (44\%) were obese $\left(>30 \mathrm{~kg} / \mathrm{m}^{2}\right)$. IGF-1 levels were significantly lower among the latter group. Together these data indicate that among subjects with CWP and FM it is those who are obese who are more likely to have lowered IGF-1 levels. Our study has demonstrated that in men this relationship was not specific to those with CWP and was unlikely to be of etiological importance. The relationship with $\mathrm{GH}$ is still unclear and deserves further investigation.

\section{ACKNOWLEDGMENT}

The authors thank the men who participated in the 8 countries; the research/nursing staff in the 8 centers: C. Pott, Manchester, E. Wouters, Leuven, M. Nilsson, Malmö, M. del Mar Fernandez, Santiago de Compostela, M. Jedrzejowska, Lodz, H-M. Tabo, Tartu, and A. Heredi, Szeged, for their meticulous data collection; and C. Moseley, Manchester, for data entry and project coordination.

The EMAS Study Group: Gianni Forti, Luisa Petrone, Antonio Cilotti, Florence; Dirk Vanderschueren, Steven Boonen, Herman Borghs, Leuven; Krzysztof Kula, Jolanta Slowikowska-Hilczer, Renata WalczakJedrzejowska, Lodz; Ilpo Huhtaniemi, London; Aleksander Giwercman, Malmö; Frederick Wu, Alan Silman, Terence O'Neill, Joseph Finn, Philip Steer, Abdelouahid Tajar, David Lee, Stephen Pye, Manchester; Felipe Casanueva, Marta Ocampo, Mary Lage, Santiago; Gyorgy Bartfai, Imre Földesi, Imre Fejes, Szeged; Margus Punab, Paul Korrovitz, Tartu; Min Jiang, Turku.

\section{REFERENCES}

1. Wolfe F, Smythe HA, Yunus MB, Bennett R, Bombardier C. The Personal non-commercial use only. The Journal of Rheumatology Copyright (C) 2009. All rights reserved. 
American College of Rheumatology 1990 criteria for the classification of fibromyalgia. Arthritis Rheum 1990;33:160-72.

2. Birtane M, Uzunca K, Tastekin N, Tuna H. The evaluation of quality of life in fibromyalgia syndrome: a comparison with rheumatoid arthritis by using SF-36 Health Survey. Clin Rheumatol 2007;26:679-84.

3. Yunus MB. Central sensitivity syndromes: a new paradigm and group nosology for fibromyalgia and overlapping conditions, and the related issue of disease versus illness. Semin Arthritis Rheum 2008;37:339-52.

4. McBeth J, Silman AJ, Gupta A, Chiu YH, Ray D, Morriss R, et al. Moderation of psychosocial risk factors through dysfunction of the hypothalamic-pituitary-adrenal stress axis in the onset of chronic widespread musculoskeletal pain: findings of a population-based prospective cohort study. Arthritis Rheum 2007;56:360-71.

5. Bennett RM, Cook DM, Clark SR.

Hypothalamic-pituitary-insulin-like-growth factor-1 axis dysfunction in patients with fibromyalgia. J Rheumatol 1997;24:1384-9.

6. Belt NK, Kronholm E, Kauppi MJ. Sleep problems in fibromyalgia and rheumatoid arthritis compared with the general population. Clin Exp Rheumatol 2009;27:35-41.

7. Jones KD, Deodhar P, Lorentzen A, Bennett RM, Deodhar AA. Growth hormone perturbations in fibromyalgia: a review. Semin Arthritis Rheum 2007;36:357-79.

8. Tander B, Atmaca A, Aliyazicioglu Y, Canturk F. Serum ghrelin levels but not GH, IGF-1 and IGFBP-3 levels are altered in patients with fibromyalgia syndrome. Joint Bone Spine 2007;74:477-81.

9. Kop WJ, Lyden A, Berlin AA, Ambrose K, Olsen C, Gracely RH, et al. Ambulatory monitoring of physical activity and symptoms in fibromyalgia and chronic fatigue syndrome. Arthritis Rheum 2005;52:296-303.

10. Hooper MM, Stellato TA, Hallowell PT, Seitz BA, Moskowitz RW. Musculoskeletal findings in obese subjects before and after weight loss following bariatric surgery. Int J Obes (Lond) 2007;31:114-20.

11. Arnold LM, Hudson JI, Keck PE, Auchenbach MB, Javaras KN, Hess EV. Comorbidity of fibromyalgia and psychiatric disorders. J Clin Psychiatry 2006;67:1219-25.

12. Franco C, Bengtsson BA, Johannsson G. The GH/IGF-1 axis in obesity: Physiological and pathological aspects. Metab Syndr Relat Disord 2006;4:51-6.

13. Morgan TM, Crawford L, Stoller A, Toth D, Yeo KT, Baron JA. Acute effects of nicotine on serum glucose insulin growth hormone and cortisol in healthy smokers. Metabolism 2004;53:578-82.

14. Dinan TG. Psychoneuroendocrinology of depression. Growth hormone. Psychiatr Clin North Am 1998;21:325-39.

15. Lanfranco F, Gianotti L, Giordano R, Pellegrino M, Maccario M, Arvat E. Ageing, growth hormone and physical performance. J Endocrinol Invest 2003;26:861-72.

16. Kaplan RC, McGinn AP, Pollak MN, Kuller L, Strickler HD, Rohan TE, et al. Total insulin-like growth factor 1 and insulin-like growth factor binding protein levels, functional status, and mortality in older adults. J Am Geriatr Soc 2008;56:652-60.

17. Dessein PH, Shipton EA, Joffe BI, Hadebe DP, Stanwix AE, van der Merwe BA. Hyposecretion of adrenal androgens and the relation of serum adrenal steroids, serotonin and insulin-like growth factor-1 to clinical features in women with fibromyalgia. Pain 1999;83:313-9.

18. Call-Hosenfeld JS, Goldenberg DL, Hurwitz S, Adler GK. Growth hormone and insulin-like growth factor-1 concentrations in women with fibromyalgia. J Rheumatol 2003;30:809-14.

19. Lee DM, O'Neill TW, Pye SR, Silman AJ, Finn JD, Pendleton N, et al. The European Male Ageing Study (EMAS): design, methods and recruitment. Int J Androl 2009;32:11-24.

20. Reuben DB, Siu AL. An objective measure of physical function of elderly outpatients. The Physical Performance Test. J Am Geriatr Soc 1990;38:1105-12.

21. Ware JE Jr, Sherbourne CD. The MOS 36-item Short-form Health Survey (SF-36). I. Conceptual framework and item selection. Med Care 1992;30:473-83.

22. Beck AT, Ward CH, Mendelson M, Mock J, Erbaugh J. An inventory for measuring depression. Arch Gen Psychiatry 1961;4:561-71.

23. Hunt IM, Silman AJ, Benjamin S, McBeth J, Macfarlane GJ. The prevalence and associated features of chronic widespread pain in the community using the 'Manchester' definition of chronic widespread pain. Rheumatology 1999;38:275-9.

24. McBeth J, Macfarlane GJ, Benjamin S, Silman AJ. Features of somatization predict the onset of chronic widespread pain: results of a large population-based study. Arthritis Rheum 2001;44:940-6.

25. Kostecka Y, Blahovec J. Insulin-like growth factor binding proteins and their functions. Endocr Regul 1999;33:90-4.

26. Veldhuis JD, Iranmanesh A. Physiological regulation of the human growth hormone $(\mathrm{GH})$-insulin-like growth factor type I (IGF-I) axis: predominant impact of age, obesity, gonadal function, and sleep. Sleep 1996;19 Suppl:S221-4.

27. Harding SM. Sleep in fibromyalgia patients: Subjective and objective findings. Am J Med Sci 1998;315:367-76.

28. Charlson ME, Pompei P, Ales KL, MacKenzie CR. A new method of classifying prognostic comorbidity in longitudinal studies: development and validation. J Chronic Dis 1987;40:373-83.

29. Bennett RM, Clark SR, Campbell SM, Burckhardt CS. Low levels of somatomedin $\mathrm{C}$ in patients with the fibromyalgia syndrome. A possible link between sleep and muscle pain. Arthritis Rheum 1992;35:1113-6.

30. Paiva ES, Deodhar A, Jones KD, Bennett R. Impaired growth hormone secretion in fibromyalgia patients: evidence for augmented hypothalamic somatostatin tone. Arthritis Rheum 2002;46:1344-50.

31. Leal-Cerro A, Povedano J, Astorga R, Gonzalez M, Silva H, Garcia-Pesquera F, et al. The growth hormone (GH)-releasing hormone insulin-like growth factor-1 axis in patients with fibromyalgia syndrome. J Clin Endocrinol Metab 1999;84:3378-81.

32. Jacobsen S, Main K, Danneskiold-Samsoe B, Skakkebaek NE. A controlled study on serum insulin-like growth factor-I and urinary excretion of growth hormone in fibromyalgia. J Rheumatol 1995;22:1138-40

33. Buchwald D, Umali J, Stene M. Insulin-like growth factor-I (somatomedin C) levels in chronic fatigue syndrome and fibromyalgia. J Rheumatol 1996;23:739-42.

34. Valkeinen H, Hakkinen K, Pakarinen A, Hannonen P, Hakkinen A, Airaksinen $\mathrm{O}$, et al. Muscle hypertrophy, strength development, and serum hormones during strength training in elderly women with fibromyalgia. Scand J Rheumatol 2005;34:309-14.

35. Jones KD, Deodhar AA, Burckhardt CS, Perrin NA, Hanson GC, Bennett RM. A combination of 6 months of treatment with pyridostigmine and triweekly exercise fails to improve insulin-like growth factor-I levels in fibromyalgia, despite improvement in the acute growth hormone response to exercise. J Rheumatol 2007;34:1103-11.

36. Bennett RM, Clark SC, Walczyk J. A randomized, double-blind, placebo-controlled study of growth hormone in the treatment of fibromyalgia. Am J Med 1998;104:227-31.

37. Burckhardt CS, Clark SR, Bennett RM. The Fibromyalgia Impact Questionnaire : development and validation. J Rheumatol 1991;18:728-33.

38. Cuatrecasas G, Riudavets C, Guell MA, Nadal A. Growth hormone as concomitant treatment in severe fibromyalgia associated with low IGF-1 serum levels. A pilot study. BMC Musculoskelet Disord 2007;8:119. 